\title{
Spontaneous Breathing or Mechanical Ventilation Alters Lung Compliance and Tissue Association of Exogenous Surfactant in Preterm Newborn Rabbits
}

\author{
KAJSA BOHLIN, RABEA K.L. BOUHAFS, CONNIE JARSTRAND, TORE CURSTEDT, \\ MATS BLENNOW, AND BENGT ROBERTSON
}

Division of Pediatrics, Department of Clinical Science [K.B., M.B.] and Department of Immunology, Microbiology and Infectious Diseases [R.K.L.B., C.J.], Karolinska University Hospital Huddinge, SE-141 86, Stockholm, Sweden; and Department of Clinical Chemistry [T.C., B.R.], Karolinska University

Hospital Solna, SE-171 76, Karolinska Institutet, Stockholm, Sweden

\begin{abstract}
ABST
In preterm infants with respiratory distress syndrome, surfactant
administration followed by immediate extubation to spontaneous
breathing with nasal continuous positive airway pressure reduces the
need for mechanical ventilation. With this treatment approach, repeated
doses of surfactant are rarely indicated. We used a rabbit model to test
the hypothesis that exogenous surfactant therapy followed by sponta-
neous breathing results in a more sustained initial treatment response
compared with treatment followed by mechanical ventilation. Preterm
rabbits (gestational age $28.5 \mathrm{~d}$ ) were treated with pharyngeal deposition
of 200 mg/kg radiolabeled surfactant $\left({ }^{14} \mathrm{C}-\mathrm{Curosurf}\right.$ ) and randomized to
$4 \mathrm{~h}$ of spontaneous breathing or mechanical ventilation or to a control
group, killed immediately after surfactant administration. With pharyn-
geal deposition, $46 \pm 10 \%$ (mean $\pm \mathrm{SEM}$ ) of the administered surfac-
tant reached the lungs. The dynamic lung-thorax compliance was
higher in spontaneously breathing compared with mechanically venti-
lated animals (median, 9.9 and $0.75 \mathrm{ml} \cdot \mathrm{cm} \mathrm{H}_{2} \mathrm{O}^{-1} \cdot \mathrm{kg}{ }^{-1}$, respec-
tively; $p<0.05$ ). The relative distribution of ${ }^{14} \mathrm{C}-\mathrm{Curosurf}$ in bron-
choalveolar lavage fluid and homogenized lung tissue showed a higher
degree of tissue association in the spontaneously breathing animals [53
\end{abstract}
\pm 4 versus $26 \pm 3 \%$ (mean \pm SEM)] than in mechanically ventilated animals $(p<0.01)$, the latter figure being very similar to that of the control group $(25 \pm 5 \%)$. There was a higher degree of lipid peroxidation and fewer microbubbles in bronchoalveolar lavage fluid from mechanically ventilated animals. We conclude that the initial lung tissue association of exogenous surfactant is impaired by mechanical ventilation. This is associated with a reduction of dynamic compliance and evidence of increased surfactant inactivation. (Pediatr Res 57: 624 630, 2005)
BAL, bronchoalveolar lavage
MDA, malondialdehyde
MST, microbubble stability test
nCPAP, nasal continuous positive airway pressure
PEEP, positive end expiratory pressure
RDS, respiratory distress syndrome
4-HNE, 4-hydroxyalkenals

In neonates with respiratory distress syndrome (RDS), exogenous surfactant has become a standard treatment (1). In humans, the effective mode of administration is instillation into the airways. This requires intubation, which means that surfactant treatment is usually given in conjunction with mechanical ventilation. With increasing knowledge of the detrimental

Received April 6, 2004; accepted September 2, 2004.

Correspondence: Kajsa Bohlin, M.D., Department of Clinical Sciences, Division of Pediatrics, Karolinska Institutet Children's Hospital, B 57, Karolinska University Hospital, SE-141 86 Stockholm, Sweden; e-mail: kajsa.bohlin@klinvet.ki.se.

Supported by grants from the Swedish Medical Research Council (Project 3351), Konung Oscar II:s Jubileumsfond, the Swedish Freemasons, Stiftelsen Samariten, Majblommans Research Fund, and Stiftelsen Allmänna BB:s Minnesfond.

Presented in abstract form at 18th International Workshop on Surfactant Replacement, Prague, June 2003, Czech Republic; and at the European Society for Pediatric Research, September 2003, Bilbao, Spain.

DOI: 10.1203/01.PDR.0000156502.84909.BC effects of mechanical ventilation on the immature lung, there is a need for alternative treatment approaches. Early nasal continuous positive airway pressure (nCPAP) has been shown to be beneficial as initial treatment of RDS also in very low birth weight infants $(2,3)$. With the administration of exogenous surfactant during a short intubation, followed by immediate extubation to nCPAP, the need for mechanical ventilation is reduced in preterm infants with $\operatorname{RDS}(4,5)$. In most of these patients, a single dose of surfactant is sufficient to reverse the clinical course of RDS, whereas in mechanically ventilated infants, multiple doses are often required (6). On the basis of these clinical observations, we hypothesized that the duration of the treatment response would be better and more sustained if infants were allowed to breathe spontaneously after receiving surfactant rather than being subjected to mechanical ventilation. 
Mechanical ventilation induces varying degrees of lung injury, resulting in fluid leakage and inflammatory response, which can inactivate both endogenous and exogenous surfac$\operatorname{tant}(7,8)$. Oxidative reactions that lead to lipid peroxidation of surfactant have been proposed as one mechanism for this inactivation $(9,10)$. For assessing surfactant inactivation induced by plasma proteins, the microbubble stability test (MST) performed on bronchoalveolar lavage (BAL) fluid or gastric aspirates of the newborn provides a rapid test that can also be used to predict the later development of RDS $(11,12)$. Dynamic lung compliance, reflecting surfactant function and activity, has long been used to evaluate treatment response (13). In surfactant-treated preterm rabbits that are ventilated with standardized insufflation pressure, tidal volume decreases with increasing time of mechanical ventilation. The change in tidal volume is also associated with an elevation of surface tension in lung lavage fluid, suggesting inactivation of surfactant (14). Compliance measurements in surfactant-treated animals that breathe spontaneously are sparse (15). In neonates with RDS, studied during spontaneous breathing with nCPAP, dynamic compliance increased by $29 \%$ after exogenous surfactant treatment, but during mechanical ventilation, no improvement could be detected (16).

Ventilation strategy can clearly alter the treatment response of exogenous surfactant. Mechanical ventilation with large tidal volumes before surfactant administration compromises the therapeutic effect (17), whereas application of positive end expiratory pressure (PEEP) may decrease the protein leaks into the alveoli (18) and increase compliance in ventilated, immature lungs (19). Although surfactant metabolism in relation to ventilation strategy has been studied extensively, there are few comparative experimental studies versus CPAP and spontaneous breathing. One recent report indicated decreased lung injury in CPAP-treated premature lambs compared with animals that underwent mechanical ventilation (20). In preterm infants, surfactant replacement followed by spontaneous breathing in nCPAP is now an established option, and this treatment strategy results in a good treatment response and seems to be beneficial compared with mechanical ventilation (21). To evaluate our hypothesis in a controlled, laboratory setting, we designed a series of experiments in preterm newborn rabbits to test whether the treatment response pattern, including tissue association, function, and inactivation of exogenous surfactant in the first $4 \mathrm{~h}$ of postnatal life, would differ after spontaneous breathing or mechanical ventilation.

\section{METHODS}

Surfactant preparation. Curosurf, a commercially available surfactant derived from porcine lungs, was provided by Chiesi Farmaceutici (Parma, Italy). The lipids and hydrophobic proteins in Curosurf were isolated by extraction according to Bligh and Dyer (22) and mixed with 1-palmitoyl-2$\left[1-{ }^{14} \mathrm{C}\right]$ palmitoyl phosphatidylcholine (specific activity $54-55.5 \mathrm{mCi} / \mathrm{mmol}$; Amersham Biosciences, Little Chalfont, Buckinghamshire, UK), dried under $\mathrm{N}_{2}$, and suspended in saline. Three batches of radiolabeled surfactant $\left({ }^{14} \mathrm{C}-\right.$ Curosurf) were used, one was provided by Dr. Aldo Baritussio (University of Padua, Padua, Italy) and two were prepared in our laboratory. The final suspensions had a concentration of $80 \mathrm{mg} / \mathrm{mL}$ and contained $28,000-35,000$ $\mathrm{dpm} / \mathrm{mg}$.

Animal experiments. The experiments were performed on seven litters with a total of 54 rabbit fetuses delivered at a gestational age of $28.5 \mathrm{~d}$ (term $31 \mathrm{~d}$ ).
This represents a transitional stage of lung maturation at which the fetal rabbits have started to produce surfactant (23). Furthermore, pups that are delivered prematurely at this stage of gestation have sufficient respiratory drive to support spontaneous breathing for several hours (24). The does were anesthetized with i.v. propophol and local infiltration of the abdominal wall with lidocaine. The fetuses were sequentially obtained by hysterotomy, and thorax compression was immediately applied to prevent breathing. A thin plastic catheter was introduced to the pharynx, and $0.1 \mathrm{~mL}$ (corresponding to 200 $\mathrm{mg} / \mathrm{kg}$ ) of ${ }^{14} \mathrm{C}$-Curosurf was deposited with simultaneous release of the thorax compression and cutaneous stimulation to induce breathing. After aspiration, when there was no visible surfactant left in the pharynx, the animals were weighed and placed in a box heated to $37^{\circ} \mathrm{C}$ and flushed with $100 \%$ oxygen. The duration of the procedure was 1-2 min. The next fetus was not delivered until the first had received surfactant. Animals in which $<10 \%$ of the administered dose was delivered to the lungs were excluded $(n=10)$. The experimental set up is shown schematically in Fig. 1.

The animals were randomized to 1$)$ mechanical ventilation $(n=18), 2)$ spontaneous breathing $(n=18)$, or 3$)$ control group $(n=8)$. Animals that were randomized to mechanical ventilation were anesthetized with i.p. pentobarbital sodium $(0.1 \mathrm{~mL}, 6 \mathrm{mg} / \mathrm{mL})$ and tracheotomized. They then were transferred to a system of multiple body plethysmographs heated to $37^{\circ} \mathrm{C}(13)$. After muscle relaxation with i.p. pancuronium bromide $(0.1 \mathrm{~mL}, 0.2 \mathrm{mg} / \mathrm{mL})$, they were connected in parallel to a pressure-constant ventilator system (Servo Ventilator 900 B; Siemens-Elema, Solna, Sweden), delivering 100\% oxygen at a frequency of 40/min and 1:1 inspiration:expiration ratio. Using a Powerlab system (ADInstruments Limited, Chalgrove, Oxfordshire, UK) including Powerlab 4/20 (ML840), Bridge AmpT (ML110), Animal Bio Amp (ML136), and Spirometer (ML140), the pressure of the respiratory circuit, individual flow rates/tidal volumes, and ECGs were recorded. For individual pressure measurements, a pressure transducer (MLT844) was used. The inspiratory pressure was set to generate a tidal volume of $10 \mathrm{~mL} / \mathrm{kg}$ and was monitored and adjusted regularly during the observation period. ECG indicating severe arrhythmia or bradycardia $<50$ beats/min was regarded as exclusion criterion $(n=7)$.

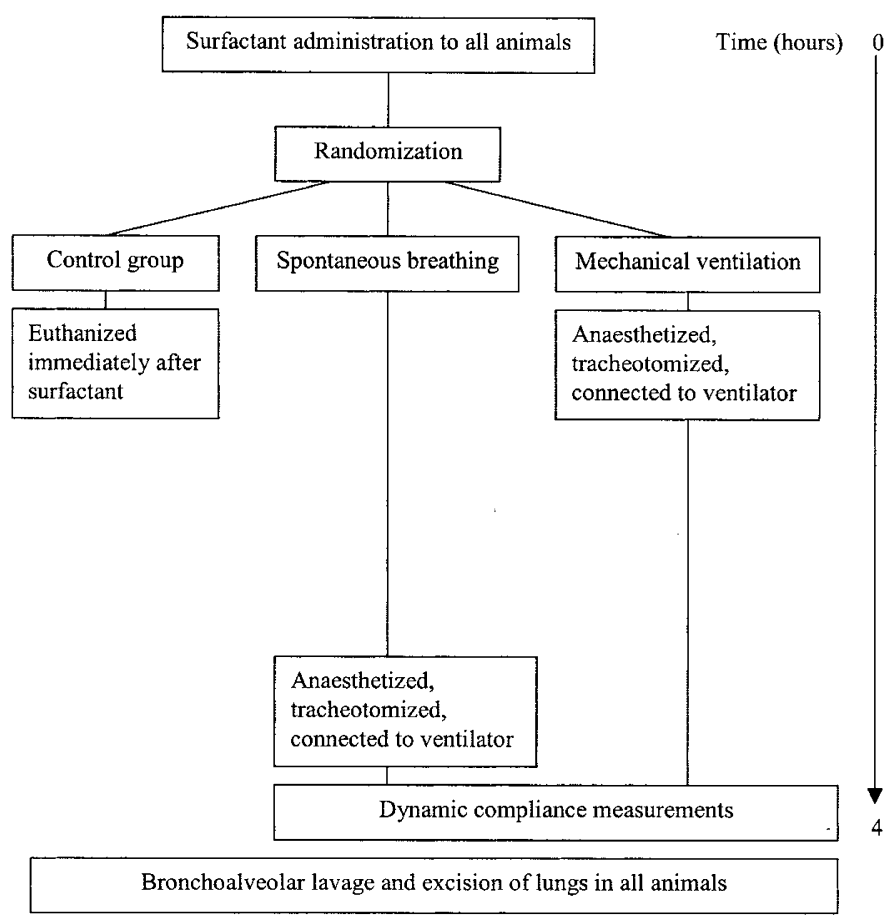

Figure 1. Experimental set-up. Schematic view of the experiment. A total of 54 premature rabbits received $0.1 \mathrm{~mL}$ of ${ }^{14} \mathrm{C}$-Curosurf $(\sim 200 \mathrm{mg} / \mathrm{kg})$ by pharyngeal deposition before their first breath. Control animals were killed immediately after surfactant administration. After anesthesia with pentobarbital sodium, tracheotomy, and muscle relaxation with pancuronium bromide, mechanically ventilated animals were ventilated with a tidal volume of 10 $\mathrm{mL} / \mathrm{kg}$. At the end of the experiment, spontaneously breathing animals were anesthetized and tracheotomized as previously the mechanically ventilated and dynamic compliance measurements were performed at $4 \mathrm{~h}$ of life in both groups. 
Spontaneously breathing animals were kept in the heated box during the 4-h observation period. Subjects that failed to establish spontaneous regular breathing or developed irregular breathing were excluded when the respiratory rate was $<6$ breaths/min $(n=3)$. At the end of the observation period, the spontaneously breathing animals were anesthetized with i.p. pentobarbital sodium $(0.1 \mathrm{~mL}, 6 \mathrm{mg} / \mathrm{mL})$, tracheotomized, muscle relaxed with i.p. pancuronium bromide $(0.1 \mathrm{~mL}, 0.2 \mathrm{mg} / \mathrm{mL})$, and connected to the ventilatormultiplethysmograph system. Dynamic lung-thorax compliance was measured at $4 \mathrm{~h}$ of life in both mechanically ventilated and spontaneously breathing animals by dividing tidal volume $(\mathrm{mL} / \mathrm{kg})$ by peak inspiratory pressure $(\mathrm{cm}$ $\mathrm{H}_{2} \mathrm{O}$ ) for individual animals in each treatment group. After compliance measurements, animals were killed by intracerebral injection of lidocaine $(2 \%, 0.5$ $\mathrm{mL}$ ). Control animals were similarly killed immediately after instillation of ${ }^{14} \mathrm{C}$-Curosurf. The study was approved by the Karolinska Institutet Animal Ethics Committee, Stockholm.

Lung preparations. BAL was performed in all animals, using $40 \mathrm{~mL} / \mathrm{kg}$ normal saline that was instilled and withdrawn three times. The procedure was repeated five times, and the washes were pooled. The total BAL volume was recorded, and an average of $93 \pm 1 \%$ (mean \pm SEM) of the instilled volume was recovered. Aliquots of the BAL fluid were mixed with chloroform:methanol (1:2:2 BAL fluid/chloroform/methanol) for radioactivity measurements. The remaining fluid was frozen at $-20^{\circ} \mathrm{C}$ for analysis of total phospholipid content and microbubble stability and at $-70^{\circ} \mathrm{C}$ for measurement of lipid peroxidation. The lavaged lungs were removed, weighed, mechanically homogenized in chloroform/methanol 1:1, filtered, and mixed with distilled water to final proportions of chloroform/methanol/water $(2: 2: 1)$.

Radioactivity measurements. The organic phases of BAL fluid and lung tissue samples were used in duplicate for radioactivity measurements in a 1215 Rackbeta II Liquid Scintillant Counter (LKB/Wallac Og, Turku, Finland). The total recovery from the lungs (i.e. the dose of ${ }^{14} \mathrm{C}$-Curosurf deposited to the lungs) was calculated by dividing the sum of the radioactivity (counts per minute) in BAL fluid + lung tissue from each animal with the administered dose of radioactivity. The degree of tissue association of exogenous surfactant was determined by the distribution of ${ }^{14} \mathrm{C}$-Curosurf in $\mathrm{BAL}$ fluid and lung tissue, calculated as the ratio of radioactivity in BAL fluid or lung tissue relative to the dose deposited (radioactivity in BAL fluid + lung tissue) and is expressed in percentage.

The total phosphorus content in the BAL fluid was measured according to Bartlett (25). An estimation of the alveolar pool of endogenous surfactant was made by subtracting the amount of exogenous surfactant (total recovery of ${ }^{14} \mathrm{C}$-Curosurf) from the total phosphorus content in the BAL fluid and relating it to the weight of the individual animal.

Lipid peroxidation and surfactant inactivation. The degree of lipid peroxidation in the BAL fluid was determined by measuring the amounts of secondary products such as malondialdehyde (MDA) and 4-hydroxyalkenals (4-HNE) using a new LPO-586 colorimetric assay (OXIS-21012; British Biotechnology Products Ltd., Abingdon, UK). The principle is based on the reaction of a chromogenic reagent (R1; $10.3 \mathrm{mM} \mathrm{N}$-methyl-2-phenylindole) in acetonitrile, with MDA and 4-HNE to yield a stable chromophore with a maximal absorbance at $586 \mathrm{~nm}(26,27)$. To adjust for differences between litters, the value of each sample was divided by the mean value of the litter, giving a lipid peroxidation score.

The MST was performed in a subgroup of animals (three litters, $n=15$ ). After thawing, bubbles were generated in BAL samples by sucking and expelling the fluid in and out of a Pasteur pipette, $1 \mathrm{~mm}$ in diameter, 60 times during $\sim 30 \mathrm{~s}$ (28). Three droplets from the deeper part of the sample were placed in separate wells of a glass slide and covered with a coverslip. The droplets were immediately examined with a light microscope connected to an image analyzer operating at a magnification of $\times 230$. A specially designed computer program was used in the size distribution analysis of the bubbles in the samples (12). Microbubbles were defined as bubbles with diameter $<20$ $\mu \mathrm{m}$ (12). The percentage and the total number of microbubbles were calculated in six random fields (total area $3.1 \mathrm{~mm}^{2}$ ).
Data presentation. Two-tailed $t$ tests were used for normally distributed data, Wilcoxon rank sum for nonnormally distributed data, Fisher exact test for categorical data, and Pearson coefficients for correlation analysis. Data are presented as mean \pm SEM or median and interquartile range. Statistical analyses were performed using SAS (version 8.1; SAS Institute, Cary, NC).

\section{RESULTS}

Fifteen of 18 animals in the spontaneously breathing group and 11 of 18 in the mechanically ventilated group survived the 4-h experiment, resulting in a survival rate of $83 \%$ for the spontaneously breathing animals compared with $61 \%$ for the mechanically ventilated $(p=0.26)$.

The total recovery of ${ }^{14} \mathrm{C}$-Curosurf from the lung (BAL fluid + lung tissue) was $46 \pm 10 \%$ in the control group, indicating that, with pharyngeal deposition, approximately half of the administered dose reached the lungs. This corresponds to an average dose of $92 \mathrm{mg} / \mathrm{kg}$. There were no significant differences in the treatment groups after $4 \mathrm{~h}$, suggesting minimal or no clearance from the lung. The total recovery of ${ }^{14} \mathrm{C}$-Curosurf in the different treatment groups, together with a description of birth weight and the estimated alveolar pool of endogenous surfactant, is shown in Table 1.

The distribution of ${ }^{14} \mathrm{C}$-Curosurf in BAL fluid and lung tissue differed between the treatment groups (Fig. 2). In the spontaneously breathing group, $53 \pm 4 \%$ of the ${ }^{14} \mathrm{C}$-Curosurf was tissue associated, i.e., could not be recovered by lavage after $4 \mathrm{~h}$, compared with $26 \pm 3 \%$ in the mechanically ventilated group $(p<0.001)$. The immediate tissue association was found to be $25 \pm 5 \%$ in the control group, which is very similar to that found for the mechanically ventilated animals after $4 \mathrm{~h}$. There was a weak but statistically significant correlation between the degree of tissue association and dynamic lung-thorax compliance $(r=0.41, p=0.04)$.

Median and interquartile range values for dynamic lungthorax compliance in the spontaneously breathing and mechanically ventilated animals were $0.90 \mathrm{ml} \cdot \mathrm{cm} \mathrm{H}_{2} \mathrm{O}^{-1} \cdot \mathrm{kg}^{-1}$. $(0.76-1.13)$ and $0.75 \mathrm{ml} \cdot \mathrm{cm} \mathrm{H}_{2} \mathrm{O}^{-1} \cdot \mathrm{kg}^{-1} \cdot(0.70-0.80)$, respectively ( $p<0.05$; Fig. 3 ). There was no difference in compliance values between litters; the animals with the five highest values came from four different litters. No correlation between the total recovery of ${ }^{14} \mathrm{C}$-Curosurf and dynamic lungthorax compliance could be found (data not shown).

The amount of MDA and 4-HNE in BAL fluid ranged between 0.19 and $6.95 \mu \mathrm{mol} / \mathrm{mL}$. The lipid peroxidation score revealed a higher degree of lipid peroxidation in the mechanically ventilated group compared with the spontaneously breathing animals [1.26 (1.10-1.66) versus $0.99(0.80-1.12)$; $p<0.01]$. These values were both significantly higher than

Table 1. Characteristics of the treatment groups

\begin{tabular}{lccc}
\hline \multicolumn{1}{c}{ Treatment group } & $\begin{array}{c}\text { Birth weight } \\
(\mathrm{g})\end{array}$ & $\begin{array}{c}\text { Endogenous surfactant } \\
\text { pool }(\mathrm{mg} / \mathrm{kg}) *\end{array}$ & $\begin{array}{c}\text { Total recovery of } \\
{ }^{14} \mathrm{C}-\text { Curosurf }(\%) \dagger\end{array}$ \\
\hline Spontaneous breathing $(n=15)$ & $38 \pm 1$ & $7.7 \pm 1.2$ & $39 \pm 4$ \\
Mechanical ventilation $(n=11)$ & $37 \pm 2$ & $9.0 \pm 1.4$ & $47 \pm 5$ \\
Control animals $(n=8)$ & $32 \pm 3$ & $8.2 \pm 3.0$ & $46 \pm 10$ \\
\hline
\end{tabular}

Values are mean \pm SEM.

* Amount of phosphorus minus exogenous surfactant $\left({ }^{14} \mathrm{C}\right.$-Curosurf) in BAL fluid per kilogram of body weight. No statistical difference between groups.

$\dagger$ Total recovery of radioactivity in BAL fluid + lung tissue relative to the administered dose of ${ }^{14} \mathrm{C}$-Curosurf. No statistical difference between groups. 


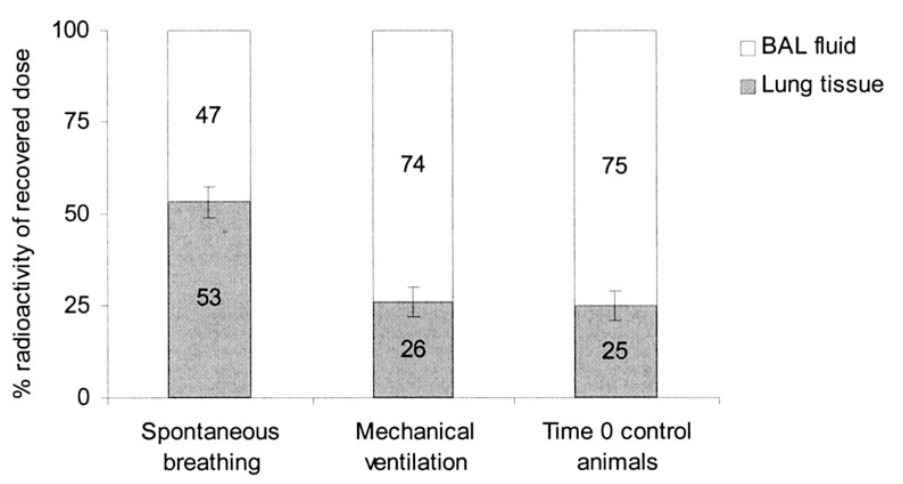

Figure 2. Lung distribution of exogenous surfactant. The relative distribution of ${ }^{14} \mathrm{C}$-Curosurf in BAL fluid and lung tissue, expressed as percentage of total recovery. The degree of tissue association of surfactant, i.e. radiolabel found in lung tissue $4 \mathrm{~h}$ after surfactant administration, was significantly higher in spontaneously breathing animals $(n=15)$ compared with both mechanically ventilated $(n=11)$ and control animals $(n=8 ; p<0.001)$. Error bars indicate SEM in both BAL fluid and lung tissue.

that of the control group [0.50 (0.18-0.88); $p<0.05$; Table 2]. MST showed an overall high percentage of microbubbles but with a trend toward lower values for the mechanically ventilated [88\% (63-93)] compared with the spontaneously breathing group [95\% (91-100); $p=0.11$; Table 2].

\section{DISCUSSION}

We have shown that in spontaneously breathing rabbits, exogenous surfactant has a greater tissue association and a higher dynamic compliance compared with mechanically ventilated animals. In the very premature infant, early CPAP is a treatment approach that allows spontaneous breathing and promotes uniform alveolar expansion. With this mode of ventilatory support, lung mechanics is improved and the need for mechanical ventilation is reduced $(4,16)$. However, to date, there are few experimental studies to support the benefits of nCPAP. Jobe et al. (20) found fewer neutrophils and lower levels of hydrogen peroxide in alveolar washes from CPAPtreated preterm lambs compared with mechanically ventilated animals, indicating less lung injury in the former group, data that are supported by our results. In our rabbit model, application of CPAP to spontaneously breathing animals was not feasible, and the use of PEEP would have been a confounder if applied to mechanically ventilated animals only. Therefore, we did not use PEEP in the ventilator settings. This might have impaired the treatment response to exogenous surfactant. Rider et al. (18) showed that application of PEEP in surfactanttreated preterm newborn rabbits decreased the recovery of intravascular labeled albumin in the lungs, indicating less lung injury. This was associated with a trend toward improved dynamic compliance, which, however, was not statistically significant. Along the same lines, Michna et al. (19) reported increased compliance in surfactant-treated, very preterm lambs that were ventilated with $4-7 \mathrm{~cm} \mathrm{H}_{2} \mathrm{O}$ of PEEP compared with zero PEEP. To the best of our knowledge, there are no published experimental studies of pulmonary mechanics and lung injury in spontaneously breathing subjects with and without CPAP.
The term ventilator-induced lung injury is used to describe the pathophysiologic changes of altered lung fluid balance, endothelial and epithelial leakage, and various degree of tissue damage that occur during mechanical ventilation, all of which interact with the pulmonary surfactant system (7). A recent clinical trial identified mechanical ventilation as the major risk factor for bronchopulmonary dysplasia, one of the most important complications in surfactant-deficient, premature infants (29). In the effort to reduce ventilator-induced lung injury, much attention has been focused on lung-protective ventilation strategies, and avoiding volutrauma from alveolar overdistension has become recognized as one of the most important issues (30). A tidal volume of $10 \mathrm{~mL} / \mathrm{kg}$, as we used in this animal study, would in a clinical setting be considered excessive, predisposing to lung injury. Our present protocol for mechanical ventilation was based on previous experience with the ventilator system at hand, in which the therapeutic effect of surfactant treatment was evaluated in preterm rabbits that were $27.5 \mathrm{~d}$ of gestational age and ventilated with a tidal volume of $8-10 \mathrm{~mL} / \mathrm{kg}$ without histologic evidence of lung injury (13). All animals in the present study received prophylactic surfactant treatment, which in previous studies has been shown to protect against ventilator-induced lung injury. Nilsson et al. (31) reported that rabbit pups that were delivered at a gestational age of $27 \mathrm{~d}$ and treated with surfactant at birth could be ventilated for $1 \mathrm{~h}$ with tidal volumes of $10 \mathrm{~mL} / \mathrm{kg}$ and zero PEEP, without the histologic evidence of lung injury found in untreated controls. Wada et al. (32) reported that in preterm lambs, an initial tidal volume of $20 \mathrm{~mL} / \mathrm{kg}$ decreased the subsequent response to surfactant treatment, an effect that was prevented with surfactant treatment at birth. In surfactanttreated preterm lambs that were ventilated for up to $24 \mathrm{~h}$, a high tidal volume $(15 \mathrm{~mL} / \mathrm{kg})$ and low rate $(15$ breaths $/ \mathrm{min})$ compared with a low tidal volume $(8 \mathrm{~mL} / \mathrm{kg})$ and high rate $(50$ breaths/min) did not influence alveolar lavage protein or sur-

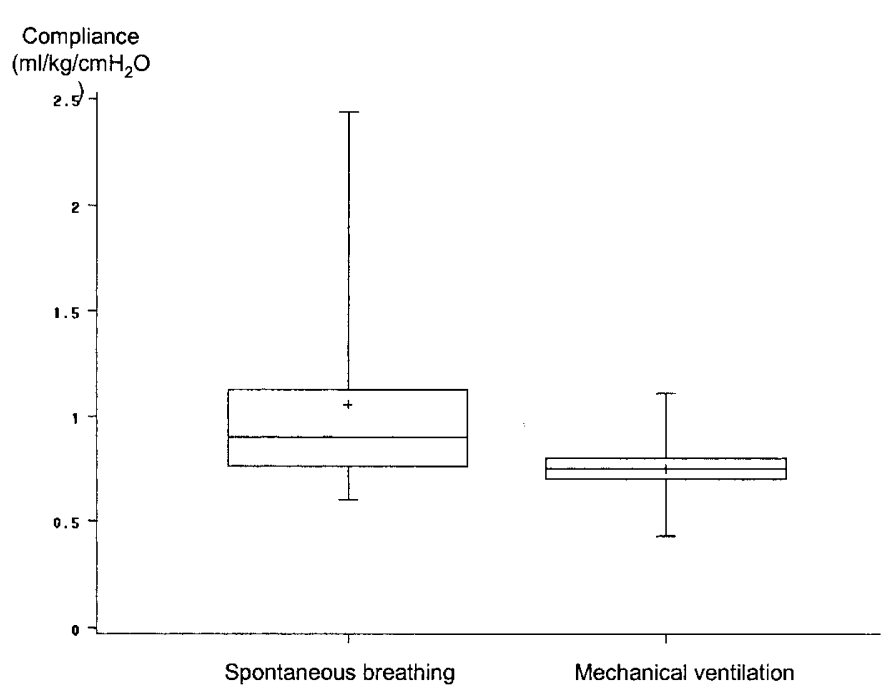

Figure 3. Dynamic lung-thorax compliance $4 \mathrm{~h}$ after surfactant administration in spontaneously breathing $(n=15)$ and mechanically ventilated $(n=11)$ surfactant-treated preterm rabbits. Box depicts interquartile range; the horizontal line marks the median value, + marks the mean values, and the vertical line marks the range. Compliance was greater for spontaneously breathing than mechanically ventilated animals $(p<0.05)$. 
Table 2. Indicators of surfactant inactivation

\begin{tabular}{|c|c|c|c|c|}
\hline & $\begin{array}{l}\text { Mechanical } \\
\text { ventilation }\end{array}$ & $\begin{array}{l}\text { Spontaneous } \\
\text { breathing }\end{array}$ & Controls & $p$ value* \\
\hline $\begin{array}{l}\text { Lipid peroxidation score } \dagger \\
\qquad(n=34)\end{array}$ & $1.26(1.10-1.66)$ & $0.99(0.80-1.12)$ & $0.50(0.18-0.88)$ & $<0.01$ \\
\hline $\operatorname{MST} \ddagger(\%)(n=14)$ & $88(63-93)$ & $95(91-100)$ & $98(55-99)$ & 0.11 \\
\hline
\end{tabular}

Values are median (interquartile range).

* Mechanical ventilation compared with spontaneous breathing.

$\dagger$ Micromole of MDA and 4-HNE in BAL sample normalized to the mean value in each litter.

$\ddagger$ MST with microbubbles defined as bubble size $<20 \mu \mathrm{m}$ in diameter.

factant function when subsequently tested in premature rabbits (33). In our present study, we chose slightly more mature animals with a gestational age of $28.5 \mathrm{~d}$ compared with the 26 or $27 \mathrm{~d}$ used in many previous studies. The main reason for this was the inability of more immature animals to maintain spontaneous breathing for $4 \mathrm{~h}$, but, in addition, the more mature lungs are less susceptible to lung injury. Healthy, surfactantsufficient lungs seem to tolerate even ventilation with forced expiration well, as shown by Taskar et al. (34) in adult rabbits that were ventilated for $1 \mathrm{~h}$ with negative end expiratory pressure and a tidal volume of $10 \mathrm{~mL} / \mathrm{kg}$ with unchanged dynamic compliance and no histologic signs of inflammation or epithelial disruption. The median dynamic compliance of $0.75 \mathrm{~mL} \cdot \mathrm{cm} \mathrm{H}_{2} \mathrm{O}^{-1} \cdot \mathrm{kg}^{-1}$ in our mechanically ventilated group is similar to that of $0.71 \mathrm{~mL} \cdot \mathrm{cm} \mathrm{H}_{2} \mathrm{O}^{-1} \cdot \mathrm{kg}^{-1}$ in surfactant-treated near-term rabbits (gestational age $30 \mathrm{~d}$ ) that were ventilated for $30 \mathrm{~min}$ with tidal volumes of $8-10 \mathrm{~mL} / \mathrm{kg}$, without developing morphologic signs of lung injury (13). Thus, the ventilator settings used in our moderately immature animals were not injurious under the present experimental conditions, especially as the animals were treated with surfactant at birth. However, the results suggest that the negative effects of mechanical ventilation are still significant when compared with spontaneous breathing.

Previous studies in newborn rabbits have shown that between 24 and $44 \%$ of the surfactant lipid instilled into the airways immediately becomes "tissue-associated," i.e. cannot be recovered by BAL $(14,35-38)$. We found the immediate tissue association of administered surfactant to be $\sim 25 \%$, which is in agreement with previous reports. In the mechanically ventilated group, the amount of tissue-associated surfactant stayed at $\sim 25 \%$ during the 4 -h observation period, whereas in the spontaneously breathing group, there was an increase up to $>50 \%$ becoming tissue associated. The distribution of radioactivity being similar in the mechanically ventilated group and in controls killed at time 0 suggests that mechanical ventilation impairs or delays the process of continuous tissue association/uptake that takes place in animals that are allowed to breathe spontaneously. The larger alveolar pool in the mechanically ventilated animals did not improve lung function as measured by dynamic compliance. The lower dynamic compliance after $4 \mathrm{~h}$, compared with the spontaneously breathing group, is instead likely to reflect surfactant inactivation. This is supported by the lower percentage of microbubbles and higher degree of lipid peroxidation in BAL fluid from mechanically ventilated animals. Peroxidation of surfactant lipids can be induced in preterm infants by increased plasma levels of nonprotein bound iron or, at least under in vitro conditions, by free radical production from activated phagocytes or bacteria $(9,10,26,27)$. Our present data suggest that mechanical ventilation causes lipid peroxidation of surfactant either by increased production or reduced clearance of free oxygen radicals.

Many authors have described the rapid tissue association of surfactant after intratracheal administration, but its functional significance remains unclear $(14,35-38)$. To explain this phenomenon simply by inadequacy of the lavage technique is not sufficient in light of the results of this study, in which the same procedure produced different results in different treatment groups. Presumably, the tissue association reflects the entering of exogenous surfactant into the metabolic pathways of endogenous surfactant and therefore is a desired process. However, the first immediate loss of administered surfactant that is not recoverable by lavage seems to be due to binding rather than uptake. It has been suggested that the lipids and proteins of surfactant are "sticky" and adhere to the epithelial surface, with a preference to alveolar type II cells (39). Immaturity and severity of lung disease increase the tissue association in lambs, but this is linked to lower total recovery from the lungs and might instead reflect increased clearance (40). In the spontaneously breathing preterm or 3-d-old rabbit, the distribution of intratracheally administered, radiolabeled surfactant shows a dramatic change during the first $3 \mathrm{~h}$, when a significant amount of label disappears from the airspaces and becomes tissue associated. After that, the amount of label recovered in the lavage reaches a fairly stable level, increasing only slowly over $24 \mathrm{~h}$, presumably as a result of surfactant recycling $(36,37)$. In the newborn animal, surfactant is recycled with $>90 \%$ efficiency, but the time point when intratracheally administered surfactant reappears in the alveoli after recycling remains to be determined (41). Studies indicate that it takes several hours before the recovery of surfactant in alveolar washes is influenced by significant amounts of recycled material and that mechanical ventilation may hinder resecretion in preterm rabbits $(36,37)$. Thus, the recovery of surfactant in alveolar washes after $4 \mathrm{~h}$ is not likely to be significantly influenced by recycled material.

In this study, exogenous surfactant was administered by pharyngeal deposition. Puncture and direct injection of surfactant into the trachea would have been preferred because it allows deposition of a more exact dose, but in our first pilot experiments, this procedure resulted in apnea, with subsequent very low survival rates for the spontaneously breathing animals. From previous experience, we know that pharyngeal 
deposition is a feasible method (42), and in the present study, we were able to demonstrate that approximately half of the administered dose reached the lungs. The variation was wide, but our calculations using total recovery all were based on individual relations for each animal, and no correlation was found between recovery and compliance values. Some of the loss may have been due to leakage and swallowing. We screened for vascular clearance of radiolabeled Curosurf in heart blood samples that were obtained from three random animals and found no detectable levels of radioactivity (data not shown). Because the total recovery was not different at 0 and $4 \mathrm{~h}$, clearance is unlikely to contribute to the loss. Others have also shown that the overall clearance of labeled phosphatidylcholine from the preterm lung is very low, consistent with minimal catabolic activity, and that there is no difference between spontaneously breathing and mechanically ventilated animals $(39,43)$. Furthermore, for ensuring treatment effect, the dose of exogenous surfactant given was large, $\sim 20$ times that of the endogenous pool. We estimated the endogenous surfactant pool to be $7.7-9.0 \mathrm{mg} / \mathrm{kg}$, which is in agreement with previous observations in preterm rabbits (35). Anesthesia was given shortly before compliance measurements to spontaneously breathing animals but $4 \mathrm{~h}$ earlier to those that were mechanically ventilated. Clinical studies regarding the influence of muscle relaxation with pancuronium on lung compliance have given conflicting results, but any negative effect is rapid and believed to be related to decreased functional residual capacity $(44,45)$. In an experimental study in pigs that were anesthetized with pentobarbital, neuromuscular blockade did not alter lung compliance (46). Therefore, it is unlikely that the results at hand were influenced to any significant degree by the timing of anesthesia.

\section{CONCLUSION}

We conclude that in premature rabbits, mechanical ventilation seems to impair or delay the tissue association of exogenous surfactant compared with spontaneous breathing. This is associated with a lower dynamic compliance and evidence of surfactant inactivation. We speculate that spontaneous breathing allows the exogenous surfactant to enter more effectively the metabolic pathways of endogenous surfactant, thereby reducing the need for repeated dosing. Extrapolated to clinical conditions, our present experimental data support the growing evidence of benefits obtained by combining surfactant treatment with early CPAP in preterm infants.

Acknowledgments. We thank Britt-Marie Linderholm for invaluable laboratory assistance.

\section{REFERENCES}

1. Collaborative European Multicenter Study Group 1988 Surfactant replacement therapy for severe neonatal respiratory distress syndrome: an international randomized clinical trial. Pediatrics 82:683-691

2. Kamper J, Wulff K, Larsen C, Lindequist S 1993 Early treatment with nasal continuous positive airway pressure in very low-birth-weight infants. Acta Paediatr 82:193-197

3. Jonsson B, Katz-Salamon M, Faxelius G, Broberger U, Lagercrantz H 1997 Neonatal care of very-low-birthweight infants in special-care units and neonatal intensive care units in Stockholm. Early nasal continuous positive airway pressure versus mechanical ventilation: gains and losses. Acta Paediatr Suppl 419:4-10
4. Verder H, Robertson B, Greisen G, Ebbesen F, Albertsen P, Lundstrom K, Jacobsen T 1994 Surfactant therapy and nasal continuous positive airway pressure for newborns with respiratory distress syndrome. Danish-Swedish Multicenter Study Group. N Engl J Med 331:1051-1055

5. Verder H, Albertsen P, Ebbesen F, Greisen G, Robertson B, Bertelsen A, Agertoft L, Djernes B, Nathan E, Reinholdt J 1999 Nasal continuous positive airway pressure and early surfactant therapy for respiratory distress syndrome in newborns of less than 30 weeks' gestation. Pediatrics 103:E24

6. Speer CP, Robertson B, Curstedt T, Halliday HL, Compagnone D, Gefeller O, Harms K, Herting E, McClure G, Reid M, et al. 1992 Randomized European multicenter trial of surfactant replacement therapy for severe neonatal respiratory distress syndrome: single versus multiple doses of Curosurf. Pediatrics 89:13-20

7. Dreyfuss D, Saumon G 1998 Ventilator-induced lung injury: lessons from experimental studies. Am J Respir Crit Care Med 157:294-323

8. Parker JC, Hernandez LA, Peevy KJ 1993 Mechanisms of ventilator-induced lung injury. Crit Care Med 21:131-143

9. Bouhafs RK, Samuelson A, Jarstrand C 2003 Lipid peroxidation of lung surfactant due to reactive oxygen species released from phagocytes stimulated by bacteria from children with cystic fibrosis. Free Radic Res 37:909-917

10. Moison RM, Palinckx JJ, Roest M, Houdkamp E, Berger HM 1993 Induction of lipid peroxidation of pulmonary surfactant by plasma of preterm babies. Lancet 341:79-82

11. Verder H, Ebbesen F, Linderholm B, Robertson B, Eschen C, Arroe M, Lange A, Grytter C, Bohlin K, Bertelsen A; Danish-Swedish Multicentre Study Group 2003 Prediction of respiratory distress syndrome by the microbubble stability test on gastric aspirates in newborns of less than 32 weeks' gestation. Acta Paediatr 92:728-733

12. Fiori H, Linderholm B, Fiori R, Robertson B 2002 Bubbles and computer-aided image analysis for evaluation of surfactant inhibition. Acta Paediatr 90:1402-1404

13. Sun B, Kobayashi T, Cursted T, Grossmann G, Robertson B 1991 Application of a new ventilator-multi-plethysmograph system for testing efficacy of surfactant replacement in newborn rabbits. Eur Respir J 4:364-370

14. Kobayashi T, Curstedt T, Grossmann G, Robertson B 1989 Inhibition of exogenous surfactant in ventilated immature newborn rabbits. Respir Physiol 76:1-12

15. Lachmann B, Grossmann G, Nilsson R, Robertson B 1981 Effect of supplementary surfactant on in vivo lung mechanics in the premature rabbit neonate. Eur J Pediatr 136:173-179

16. Davis JM, Veness-Meehan K, Notter RH, Bhutani VK, Kendig JW, Shapiro DL 1988 Changes in pulmonary mechanics after the administration of surfactant to infants with respiratory distress syndrome. N Engl J Med 319:476-479

17. Björklund LJ, Ingimarsson J, Curstedt T, John J, Robertson B, Werner O, Vilstrup CT 1997 Manual ventilation with a few large breaths at birth compromises the therapeutic effect of subsequent surfactant replacement in immature lambs. Pediatr Res 42:348 355

18. Rider ED, Jobe AH, Ikegami M, Sun B 1992 Different ventilation strategies alter surfactant responses in preterm rabbits. J Appl Physiol 73:2089-2096

19. Michna J, Jobe AH, Ikegami M 1999 Positive end-expiratory pressure preserves surfactant function in preterm lambs. Am J Respir Crit Care Med 160:634-639

20. Jobe AH, Kramer BW, Moss TJ, Newnham JP, Ikegami M 2002 Decreased indicators of lung injury with continuous positive expiratory pressure in preterm lambs. Pediatr Res 52:387-392

21. Tooley J, Dyke M 2003 Randomized study of nasal continuous positive airway pressure in the preterm infant with respiratory distress syndrome. Acta Paediatr 92:1170-1174

22. Bligh EG, Dyer WJ 1959 A rapid method of total lipid extraction and purification. Can J Med Sci 37:911-917

23. Nilsson R 1982 The artificially ventilated preterm rabbit neonate as experimental model of hyaline membrane disease. Acta Anaesthesiol Scand 26:89-103

24. Lachmann B, Grossmann G, Nilsson R, Robertson B 1979 Lung mechanics during spontaneous ventilation in premature and fullterm rabbit neonates. Respir Physiol 38:283-302

25. Bartlett GR 1959 Phosphorus assay in column chromatography. J Biol Chem 234:466-468

26. Bouhafs RK, Jarstrand C 1999 Phagocyte-induced lipid peroxidation of lung surfactant. Pediatr Pulmonol 27:322-327

27. Bouhafs RK, Jarstrand C 1999 Lipid peroxidation of lung surfactant by bacteria. Lung 177:101-110

28. Chida S, Fujiwara T 1993 Stable microbubble test for predicting the risk of respiratory distress syndrome: I. Comparisons with other predictors of fetal lung maturity in amniotic fluid. Eur J Pediatr 152:148-151

29. Van Marter LJ, Allred EN, Pagano M, Sanocka U, Parad R, Moore M, Susser M, Paneth N, Leviton A 2000 Do clinical markers of barotrauma and oxygen toxicity explain interhospital variation in rates of chronic lung disease? The Neonatology Committee for the Developmental Network. Pediatrics 105:1194-1201

30. Ricard JD, Dreyfuss D, Saumon G 2002 Ventilator-induced lung injury. Curr Opin Crit Care 8:12-20

31. Nilsson R, Grossmann G, Robertson B 1978 Lung surfactant and the pathogenesis of neonatal bronchiolar lesions induced by artificial ventilation. Pediatr Res $12 \cdot 249-255$

32. Wada K, Jobe AH, Ikegami M 1997 Tidal volume effects on surfactant treatment responses with the initiation of ventilation in preterm lambs. J Appl Physiol 83:1054 1061

33. Ikegami M, Wada K, Emerson GA, Rebello CM, Hernandez RE, Jobe AH 1998 Effects of ventilation style on surfactant metabolism and treatment response in preterm lambs. Am J Respir Crit Care Med 157:638-644

34. Taskar V, John J, Evander E, Wollmer P, Robertson B, Jonson B 1995 Healthy lungs tolerate repetitive collapse and reopening during short periods of mechanical ventilation. Acta Anaesthesiol Scand 39:370-376

35. Jobe AH, Ikegami M 1993 Surfactant metabolism. Clin Perinatol 20:683-696 
36. Alberti A, Pettenazzo A, Enzi GB, Palamidese A, Mapp C, Ventura P, Baritussio A 1998 Uptake and degradation of Curosurf after tracheal administration to newborn and adult rabbits. Eur Respir J 12:294-300

37. Stevens PA, Wright JR, Clements JA 1989 Surfactant secretion and clearance in the newborn. J Appl Physiol 67:1597-1605

38. Seidner SR, Jobe AH, Ruffini L, Ikegami M, Pettenazzo A 1989 Recovery of treatment doses of surfactants from the lungs and vascular compartments of mechanically ventilated premature rabbits. Pediatr Res 25:423-428

39. Jobe A, Rider E 1992 Catabolism and recycling of surfactant. In: Robertson B, Van Golde L, Batenburg J (eds) Pulmonary Surfactant: From Molecular Biology to Clinical Practice. Elsevier, Amsterdam, pp 313-338

40. Jobe A 1988 Metabolism of endogenous surfactant and exogenous surfactants for replacement therapy. Semin Perinatol 12:231-244

41. Jacobs H, Jobe A, Ikegami M, Conaway D 1983 The significance of reutilization of surfactant phosphatidylcholine. J Biol Chem 258:4159-4165
42. Enhorning G, Robertson B, Milne E, Wagner R 1975 Radiologic evaluation of the premature newborn rabbit after pharyngeal deposition of surfactant. Am J Obstet Gynecol 121:475-480

43. Seidner S, Rider E, Jobe A, Yamada T, Ikegami M 1992 Effects of antenatal thyrotropin-releasing hormone, antenatal corticosteroids, and postnatal ventilation on surfactant mobilization in premature rabbits. Am J Obstet Gynecol 166:15511559

44. Miller J, Law AB, Parker RA, Sundell H, Silberberg AR, Cotton RB 1994 Effects of morphine and pancuronium on lung volume and oxygenation in premature infants with hyaline membrane disease. J Pediatr 125:97-103

45. Burger R, Fanconi S, Simma B 1999 Paralysis of ventilated newborn babies does not influence resistance of the total respiratory system. Eur Respir J 14:357-362

46. Putensen C, Leon MA, Putensen-Himmer G 1994 Effect of neuromuscular blockade on the elastic properties of the lungs, thorax, and total respiratory system in anesthetized pigs. Crit Care Med 22:1976-1980 